\title{
Discovery of 2,4-dimethoxypyridines as novel autophagy inhibitors
}

Robke, Lucas; Rodrigues, Tiago; Schröder, Peter; Foley, Daniel J.; Bernardes, Gonçalo J.L.; Laraia, Luca; Waldmann, Herbert

\section{Published in:}

Tetrahedron

Link to article, DOI:

10.1016/j.tet.2018.07.021

Publication date:

2018

Document Version

Peer reviewed version

Link back to DTU Orbit

Citation (APA):

Robke, L., Rodrigues, T., Schröder, P., Foley, D. J., Bernardes, G. J. L., Laraia, L., \& Waldmann, H. (2018). Discovery of 2,4-dimethoxypyridines as novel autophagy inhibitors. Tetrahedron, 74, 4531-4537.

https://doi.org/10.1016/j.tet.2018.07.021

\section{General rights}

Copyright and moral rights for the publications made accessible in the public portal are retained by the authors and/or other copyright owners and it is a condition of accessing publications that users recognise and abide by the legal requirements associated with these rights.

- Users may download and print one copy of any publication from the public portal for the purpose of private study or research.

- You may not further distribute the material or use it for any profit-making activity or commercial gain

- You may freely distribute the URL identifying the publication in the public portal 


\section{Accepted Manuscript}

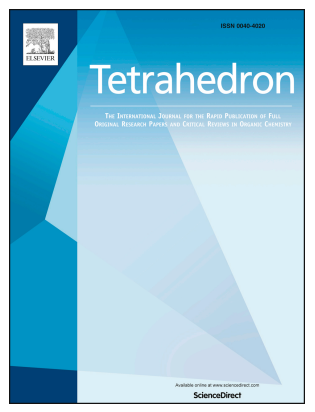

Discovery of 2,4-dimethoxypyridines as novel autophagy inhibitors

Lucas Robke, Tiago Rodrigues, Peter Schröder, Daniel J. Foley, Gonçalo J.L.

Bernardes, Luca Laraia, Herbert Waldmann

PII: S0040-4020(18)30842-1

DOI: $\quad$ 10.1016/j.tet.2018.07.021

Reference: $\quad$ TET 29681

To appear in: Tetrahedron

Received Date: 6 June 2018

Revised Date: 4 July 2018

Accepted Date: 9 July 2018

Please cite this article as: Robke L, Rodrigues T, Schröder P, Foley DJ, Bernardes GonçJL, Laraia L, Waldmann H, Discovery of 2,4-dimethoxypyridines as novel autophagy inhibitors, Tetrahedron (2018), doi: 10.1016/j.tet.2018.07.021.

This is a PDF file of an unedited manuscript that has been accepted for publication. As a service to our customers we are providing this early version of the manuscript. The manuscript will undergo copyediting, typesetting, and review of the resulting proof before it is published in its final form. Please note that during the production process errors may be discovered which could affect the content, and all legal disclaimers that apply to the journal pertain. 


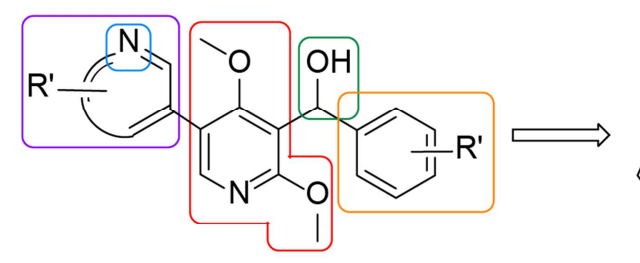<smiles>COc1ccc2ccccc2c1C(O)c1cnc(-c2cnn(Cc3ccccc3)c2)c(OC)c1C</smiles>

DMP-1

Inhibits starvation-induced autophagy 


\section{Discovery of 2,4-dimethoxypyridines as novel autophagy inhibitors}

Lucas Robke, ${ }^{a, b}$ Tiago Rodrigues, ${ }^{c}$ Peter Schröder, ${ }^{a}$ Daniel J. Foley, ${ }^{a}$ Gonçalo J. L. Bernardes, ${ }^{c, d}$ Luca Laraia, ${ }^{a, e *}$ Herbert Waldmann ${ }^{a, b *}$

aMax-Planck-Institute of Molecular Physiology, Dortmund, Germany ${ }^{b}$ Department of Chemistry and Chemical Biology of the Technical University Dortmund, Dortmund, Germany

'Instituto de Medicina Molecular, Faculdade de Medicina da Universidade de Lisboa, Av Prof Egas Moniz, 1649-028 Lisboa, Portugal

dDepartment of Chemistry, University of Cambridge, Lensfield Road, CB2 1EW Cambridge, U.K

${ }^{\mathrm{e}}$ Technical University of Denmark, Department of Chemistry, Kemitorvet, Building 207, DK-2800, Kgs. Lyngby, Denmark

*To whom correspondence should be addressed: luclar@kemi.dtu.dk, herbert.waldmann@mpi-dortmund.mpg.de

\section{Keywords}

Autophagy, phenotypic screening, high-throughput screening, natural products, medicinal chemistry

\section{Abstract}

Autophagy is a catabolic process, which mediates degradation of cellular components and has important roles in health and disease. Therefore, small molecule modulators of autophagy are in great demand. Herein, we describe a phenotypic high-content screen for autophagy inhibitors, which led to the discovery of a dimethoxypyridine-based class of autophagy inhibitors, which derive from previously reported, natural product-inspired MAP4K4 inhibitors. Comprehensive structure-activity relationship studies led to a potent 
compound, and biological validation experiments indicated that the mode of action was upstream or independent of mTOR.

\section{Introduction}

Macroautophagy (hereafter autophagy) is a highly conserved cellular process in eukaryotes, which mediates the degradation of cellular components within specialised subcellular compartments (autophagosomes). ${ }^{1-3}$ Autophagosomes derive from the phagophore, a double membrane structure that engulfs cellular components that are to be recycled. The autophagosomes subsequently fuse with lysosomes to form autophagolysosomes, in which degradation carried out by lysosomal enzymes takes place. This multistep process is tightly regulated by upstream signaling and is modulated by growth factors, the concentration of amino acids and the energy level of the cell. The purpose of this degradation is not only to compensate for a temporary lack of nutrients but also to eliminate dispensable, long-lived proteins, protein aggregates and organelles. Moreover, autophagy has been linked to microbiological infections and aging. Although primarily a protective pathway, autophagy can also be involved in cell death. Due to its involvement in these (patho)physiological processes, autophagy is an essential mechanism for the development, homeostasis and survival of cells.

Autophagy plays a crucial role in the degradation of protein aggregates, which cause several neurodegenerative diseases, including Alzheimer's, Huntington's and Parkinson's diseases. ${ }^{4-6}$ Additionally, there is evidence that autophagy is involved in the prevention of cancer by degrading toxic metabolites in the cell. ${ }^{7,8}$ However, it is also reported to promote the survival of cancer cells under conditions of nutrient deprivation. ${ }^{9-13}$ Consequently, whereas an upregulation of autophagy might serve as a preventative strategy against cancer, autophagy inhibition is a potential approach for cancer therapy after its onset. Since many unanswered questions remain regarding the dual role of autophagy in physiology and pathophysiology, there is a strong interest in a deeper understanding of its mechanisms. Selective 
autophagy modulators are valuable tools to study this process at different stages of disease. ${ }^{14-17}$ In this regard, phenotypic screening offers a useful starting point for the identification of new biologically active compounds by representing a disease relevant system. ${ }^{18-21}$

Herein we report the identification and validation of dimethoxypyridinecontaining autophagy inhibitors (DMPs) identified through a phenotypic screen. The DMPs were originally synthesised in the context of a biologyoriented synthesis (BIOS) ${ }^{22,23}$ effort to synthesise pyridones based on the natural product Militarone, which were found to be MAPK inhibitors. ${ }^{24}$ We describe a comprehensive SAR analysis, detailing the requirements for activity, in addition to biological validation experiments.

\section{Results}

\section{Phenotypic screening for autophagy inhibitors}

For monitoring and quantifying autophagy, MCF7 cells stably transfected with green fluorescent protein tagged light chain 3 (eGFP-LC3) were employed, as developed by Balgi et al. ${ }^{25-27}$ Upon autophagy induction, the ubiquitin-like cytosolic protein LC3 is conjugated to phosphatidylethanolamine (PE) and consequently recruited to the autophagosomal membrane. ${ }^{28}$ Whereas eGFPLC3, and by association the fluorescence signal, is distributed throughout the cytoplasm without autophagy induction, eGFP-LC3 accumulates at autophagosomes under starvation conditions, which can be visualised as fluorescent puncta. The puncta are detected by automated fluorescence microscopy and quantified using automated image analysis. ${ }^{25}$ Incubating the cells with Earle's balanced salt solution (EBSS) induces autophagy through amino acid starvation. Chloroquine (CQ), which is also included in the starvation medium, inhibits the fusion of autophagosomes with lysosomes, preserving eGFP fluorescence by inhibiting its degradation by the autolysosomes. This increases the dynamic range of the assay. ${ }^{29}$

As part of our ongoing programme to identify autophagy inhibitors, ${ }^{30-32}$ we identified a 2,4-dimethoxypyridine (DMP) based compound class, which 
inhibited starvation-induced autophagy (Figure 1). These compounds are synthetic precursors of a Militarinone-inspired, neuritogenic compound collection. The finding that synthetic precursors have different biological activity underlines the utility of the BIOS concept. ${ }^{33}$ We sought to explore the SAR of this compound class and optimised them for autophagy inhibition, leading to a compound we termed DMP-1 (Figure 1).<smiles>CCC(C)CC(C)/C=C(C)/C=C/C=C/C(=O)c1c(O)c(C2(O)CCC(O)CC2)cn(O)c1=O</smiles>

Militarinone A
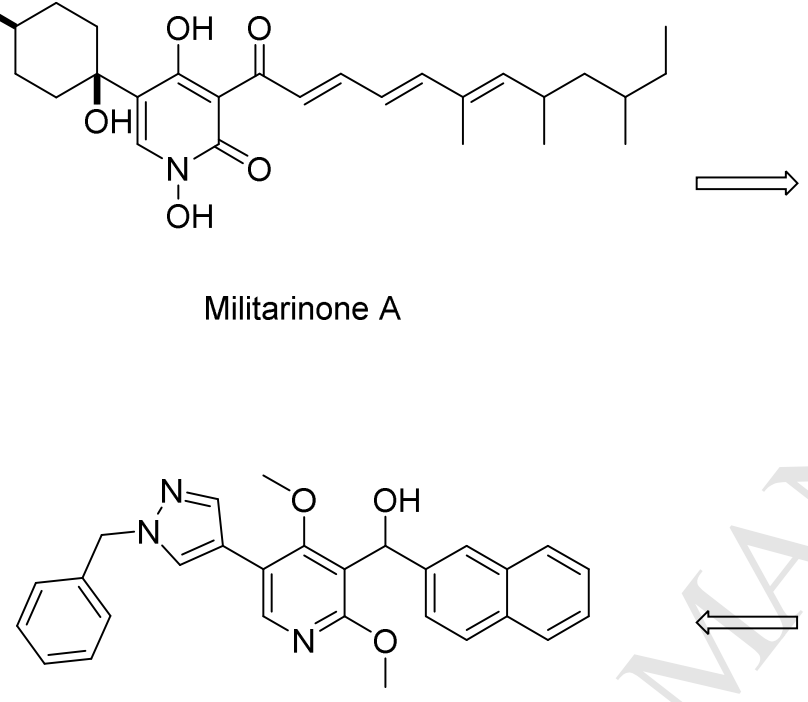$$
+
$$

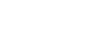

$$
\begin{gathered}
\text { DMP-1 (3) } \\
\text { Non-neuritogenic } \\
\text { Inhibits starvation induced autophagy } \\
\left(\mathrm{IC}_{50}=1.9 \pm 0.8 \mu \mathrm{M}\right)
\end{gathered}
$$

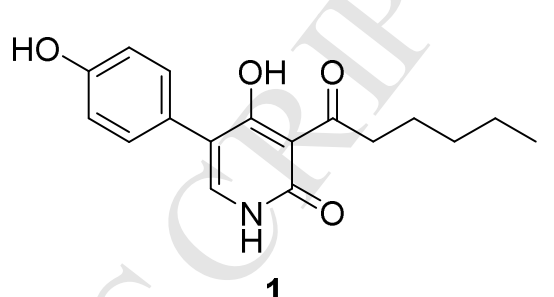

Neuritogenic Inactive in autophagy<smiles>C=C</smiles><smiles>[R]C(O)c1c(OC)ncc(-c2c[X]:[R4]cc2)c1OC</smiles>

2 hits in starvation induced autophagy

Figure 1: Structural development of an autophagy inhibitor from a neuritogenic MAP-kinase inhibitor. Dimethoxypyridine 2 represents a structural precursor for the neuritogenic MAP-kinase inhibitor 1. By varying the substitution pattern of $\mathbf{2}$ and maintaining the alcohol adjacent to the pyridine, autophagy inhibitors (including 3 ) were identified.

\section{Synthesis}

In addition to the 2,4-dimethoxypyridines that were prepared in the original study, ${ }^{24}$ further compounds of this class were synthesised, leading to $>200$ analogues (Scheme 1). The synthesis of compounds 5-11 began from 2,4dimethoxypyridine, which was reacted with bromine in acetic acid to give the versatile precursor 3,5-dibromo-2,4-dimethoxypyridine 4, which was subsequently used in the synthesis of most DMP analogues (Scheme 1). 
Bromine-lithium exchange with $s$-BuLi, followed by the addition of either an isocyanate or aldehyde electrophile, gave the amides 5 and the secondary alcohols 7 respectively. Subsequent Suzuki-Miyaura couplings yielded the analogues of type $\mathbf{6}$ and $\mathbf{8}$. Oxidation of the secondary alcohol of compounds $\mathbf{7}$ or $\mathbf{8}$ with Dess-Martin periodinane or $\mathrm{MnO}_{2}$ gave the ketones $\mathbf{1 0}$ and $\mathbf{9}$ respectively. In order to access products with different substituents at the 5position of the pyridine ring, Buchwald-Hartwig couplings were used to access products of type $\mathbf{1 1}$.
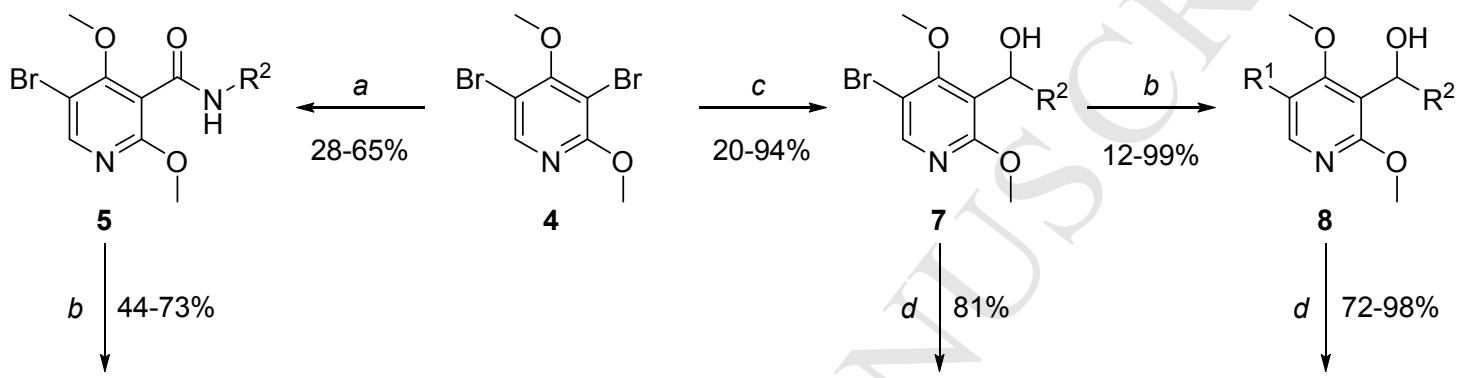

4
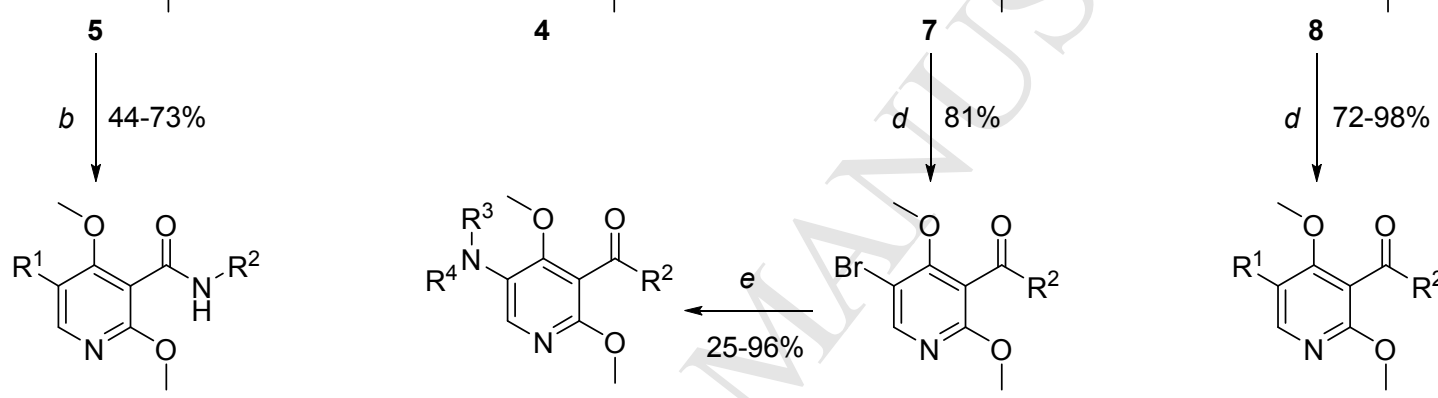

6

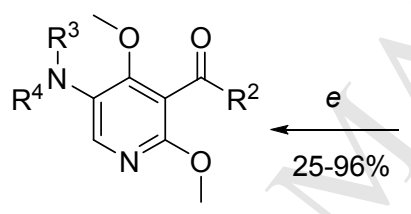

11

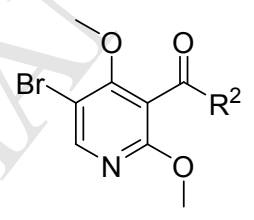

10

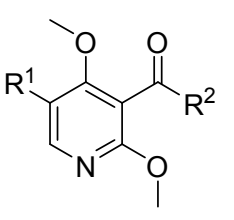

9

Scheme 1: General scheme for the synthesis of derivatives of DMP-1 and other analogues starting from precursor 4. a) $s$-BuLi, THF, $-78{ }^{\circ} \mathrm{C}, 1 \mathrm{~h}$, then $\mathrm{R}^{2} \mathrm{NCO},-78{ }^{\circ} \mathrm{C} \rightarrow \mathrm{rt}$, overnight; b) $\mathrm{R}^{1} \mathrm{~B}(\mathrm{OH})_{2}, \mathrm{Pd}\left(\mathrm{PPh}_{3}\right)_{4}$, dppf, $\mathrm{Na}_{2} \mathrm{CO}_{3}$, $\mathrm{PhMe} / \mathrm{EtOH}, \Delta, 16 \mathrm{~h}$; c) $s$-BuLi, THF, $-78^{\circ} \mathrm{C}, 1 \mathrm{~h}$, then $\mathrm{R}^{2} \mathrm{CHO},-78^{\circ} \mathrm{C} \rightarrow \mathrm{rt}$, overnight; d) $\mathrm{MnO}_{2}, \mathrm{CH}_{2} \mathrm{Cl}_{2}$, rt, 2 d or Dess-Martin periodinane, $\mathrm{CH}_{2} \mathrm{Cl}_{2}$, rt, $2 \mathrm{~h}$; e) $\mathrm{R}^{3} \mathrm{R}^{4} \mathrm{NH}$, tBuXPhos, $\mathrm{Pd}_{2} \mathrm{dba}_{3}, \mathrm{NaOtBu}, \mathrm{PhMe}, 80^{\circ} \mathrm{C}$, overnight. dppf = $1,1^{\prime}-$ Bis(diphenylphosphino)ferrocene, $\mathrm{THF}=$ tetrahydrofuran, $\mathrm{dba}=$ dibenzylidineacetone.

\section{Structure activity relationship (SAR)}

SAR was primarily investigated at the $R^{1}$ and $R^{2}$ variable groups of the 2,4dimethoxypyridines, along with further variation around the pyridine scaffold (see later). In each case, generally both the alcohol and ketone analogues at position 3 of the parent 2,4-dimethoxypyridines were investigated. Initially, 
variation at $R^{1}$ was investigated, whilst $R^{2}$ was fixed with a 2-naphthalenyl substituent (Table 1). Substitution at $R^{1}$ was found to be crucial for activity, and nitrogenous heterocycles bearing hydrophobic substituents provided the most active compounds (

Table 1, entries 1-4). For the 1- $N$-benzylpyrazole-substituted analogues investigated (Table 1, entries 1, 2, 7 and 9), substitution on the benzyl component significantly influenced potency. Phenols exhibited slightly reduced potency (Table 1, entries 5-6). Some substituted phenyls were active in the same concentration range as the phenols (Table 1, entries 8 and 1112), whilst others were inactive (entry 17). However, smaller and/or more polar substituents than the 1 - $\mathrm{N}$-benzylpyrazole ring system were not sufficient for activity (

Table 1, entries 14-16 and 19-22). The analogue where the aromatic ring substituent at $R^{1}$ was replaced with a $B r(T a b l e ~ 1$, entry 18 ) was inactive.

Table 1: Inhibition of starvation-induced autophagy determined for selected analogues with varying $R^{1}$ substituents. Where no compound number is stated and $\mathrm{IC}_{50}$ data is replaced by a dashed line, the compound has not been synthesised. $I_{50}$ data is provided as the mean $\pm S D, n \geq 3$. Where no SD is given, $n=2$. For a full list of analogues and activities see Supplementary Tables 1-6

\begin{tabular}{|c|c|c|c|c|}
\hline Entry & Alcohol & $\begin{array}{c}\text { Alcohol } \\
I_{50}[\mu \mathrm{M}]\end{array}$ & Ketone & $\begin{array}{c}\text { Ketone } \\
\mathrm{IC}_{50}[\mu \mathrm{M}]\end{array}$ \\
\hline 1 & 12 & $1.3 \pm 0.5$ & & - \\
\hline 2 & $\begin{array}{c}\text { DMP-1 } \\
\text { (3) }\end{array}$ & $1.9 \pm 0.8$ & 13 & $6.5 \pm 3.2$ \\
\hline 3 & 14 & $2.2 \pm 2.4$ & 15 & 4.1 \\
\hline
\end{tabular}




\begin{tabular}{|c|c|c|c|c|}
\hline 4 & 16 & $2.5 \pm 0.5$ & 17 & $3.9 \pm 0.4$ \\
\hline 5 & 18 & $3.8 \pm 1.0$ & 19 & - \\
\hline 6 & 20 & 3.9 & 21 & $>10$ \\
\hline 7 & 22 & $4.4 \pm 0.7$ & & - \\
\hline 8 & 23 & $4.6 \pm 0.6$ & 24 & $8.8 \pm 0.1$ \\
\hline 9 & 25 & $5.5 \pm 1.4$ & & - \\
\hline 10 & 26 & $6.5 \pm 1.6$ & 27 & $4.4 \pm 1.6$ \\
\hline 11 & 28 & $6.6 \pm 1.0$ & 29 & $8.3 \pm 0.8$ \\
\hline 12 & 30 & $7.0 \pm 0.6$ & 31 & $7.3 \pm 2.1$ \\
\hline 13 & 32 & $9.2 \pm 1.0$ & & - \\
\hline 14 & 33 & $>10$ & & - \\
\hline 15 & 34 & $>10$ & & - \\
\hline 16 & 35 & $>10$ & & - \\
\hline 17 & 36 & $>10$ & 37 & $>10$ \\
\hline 18 & 38 & $>10$ & 39 & $>10$ \\
\hline 19 & 40 & $>10$ & 41 & 3.0 \\
\hline 20 & 42 & $>10$ & & - \\
\hline 21 & 43 & $>10$ & 44 & 4.2 \\
\hline 23 & 45 & $>10$ & & - \\
\hline
\end{tabular}

Next, we turned our attention to varying the $R^{2}$ group of the 2,4dimethoxypyridines, whilst keeping the 1-benzyl-1H-pyrazol-4-yl substituent 
constant at $R^{1}$. Favourable substituents at $R^{2}$ were mostly bulky and lipophilic (Table 2, entries 1-7), and were linked to the pyridine either by a hydroxymethyl group, a ketone, or an amide. The hydroxymethyl group seems to be favoured in terms of potency when compared to the carbonyl (Table 2, entry 1). This trend was found to be consistent throughout the analogue series studied, with the exception of two pairs of compounds (Table 1, entries 20 and 22). Small, fluorine-containing aromatics retained activity (Table 2, entries 2$3)$. Efforts to reduce the size of $R^{2}$ by replacing the naphthalene ring system in the lead compounds (Table 1, entry 1-2) with a phenyl acetylene (Table 2, entry 4) led to a slightly less active analogue. Varying the size and orientation of $R^{2}$ with respect to the naphthalene on 3 , whilst retaining hydrophobicity also reduced the potency, suggesting that there are favored orientations for the hydrophobic interactions (Table 2, entries 5-7). Aromatics substituted with non-lipophilic heteroatoms were generally less active (Table 2, entries 8 and 9). Amides bearing phenyl or benzyl substituents proved to be inactive (Table 2, entries 10 and 11). Any further attempts to include more polar substituents at $R^{2}$ was not successful (Supplementary Tables 1-5).

Table 2: Inhibition of starvation-induced autophagy determined for selected analogues with variations at $R^{2}$. Where no compound number is stated and $\mathrm{IC}_{50}$ data is replaced by a dashed line, the compound has not been synthesised. $I C_{50}$ data is provided as the mean $\pm S D, n \geq 3$. Where no $S D$ is given, $n=2$. For a full list of analogues and activities see Supplementary Tables 1-6.

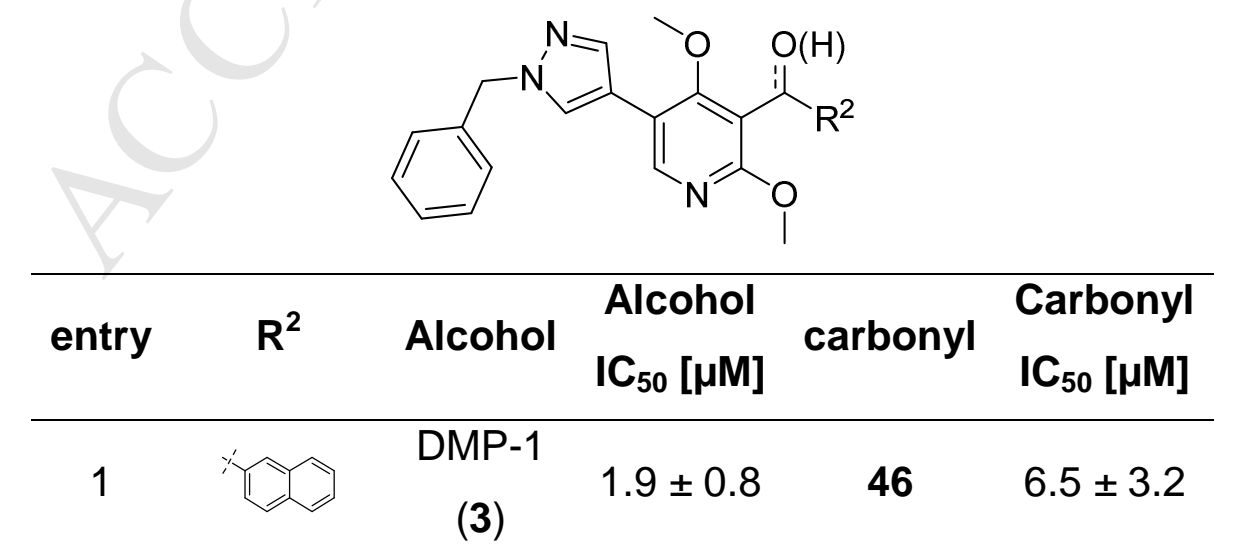




\section{ACCEPTED MANUSCRIPT}

\begin{tabular}{|c|c|c|c|c|}
\hline 2 & 47 & $2.2 \pm 2.0$ & & - \\
\hline 3 & 48 & $2.4 \pm 0.6$ & 49 & $6.4 \pm 0.6$ \\
\hline 4 & 50 & $3.3 \pm 2.5$ & & - \\
\hline 5 & & - & 51 & $4.0 \pm 1.0$ \\
\hline 6 & 52 & $4.2 \pm 1.4$ & 53 & $>10$ \\
\hline 7 & 54 & $5.5 \pm 1.5$ & & 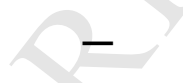 \\
\hline 8 & 55 & $5.9 \pm 1.8$ & 56 & $3.5 \pm 0.3$ \\
\hline 9 & 57 & $10 \pm 6.0$ & & - \\
\hline 10 & & - & 58 & $>10$ \\
\hline 11 & & & 59 & $>10$ \\
\hline
\end{tabular}

In final SAR studies, further variations of substituents on and around the pyridine ring were investigated. The synthesis of the different scaffold variations is detailed in Supplementary Figure 1. The two methoxy groups were both required for optimal activity, with the 2-methoxy contributing to a greater extent than the 4-methoxy substituent (entries 2-4). The pyridine nitrogen was dispensable for activity but was retained, as it was expected to increase solubility (Table 3, entry 5). Surprisingly, the presence of a methoxy group at $R^{5}$ rendered the compound inactive (Table 3, entry 6 ).

Table 3: Inhibition of starvation-induced autophagy determined for selected analogues with variation on and around the pyridine ring. $\mathrm{IC}_{50}$ data is provided as the mean $\pm S D, n \geq 3$. For a full list of analogues and activities see Supplementary Tables $1-6$. 


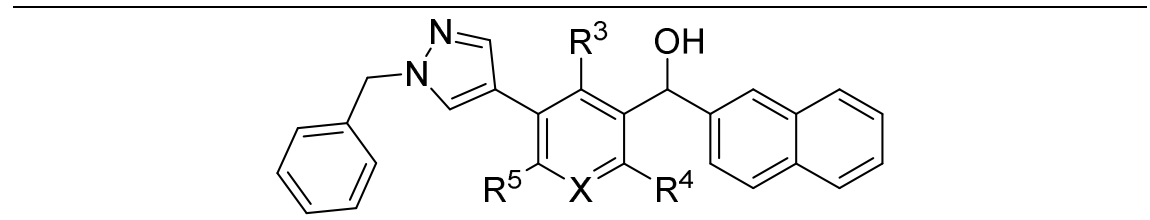

\begin{tabular}{ccccccc}
\hline Entry & Compound & $\mathbf{R}^{3}$ & $\mathbf{R}^{4}$ & $\mathbf{R}^{5}$ & $\mathbf{X}$ & $\mathbf{I C}_{50}[\boldsymbol{\mu M}]$ \\
\hline 1 & DMP-1 & OMe & OMe & H & N & $1.9 \pm 0.8$
\end{tabular}

(3)

\begin{tabular}{c|cccccc}
2 & 60 & $\mathrm{H}$ & $\mathrm{OMe}$ & $\mathrm{H}$ & $\mathrm{N}$ & $3.7 \pm 1.5$ \\
3 & 61 & $\mathrm{OMe}$ & $\mathrm{H}$ & $\mathrm{H}$ & $\mathrm{N}$ & $6.2 \pm 1.2$ \\
4 & 62 & $\mathrm{H}$ & $\mathrm{H}$ & $\mathrm{H}$ & $\mathrm{N}$ & $6.2 \pm 2.2$ \\
5 & 63 & $\mathrm{OMe}$ & $\mathrm{OMe}$ & $\mathrm{H}$ & $\mathrm{CH}$ & $1.8 \pm 0.8$ \\
6 & 64 & $\mathrm{H}$ & $\mathrm{OMe}$ & $\mathrm{OMe}$ & $\mathrm{N}$ & $>10$ \\
\hline
\end{tabular}

Overall, we generated a library that allowed us to thoroughly explore the SAR around the dimethoxypyridine scaffold (Figure 2). We selected DMP-1 (3) as a representative inhibitor to further validate this class of compounds as inhibitors of autophagy due to its favourable potency, solubility and ease of synthesis.

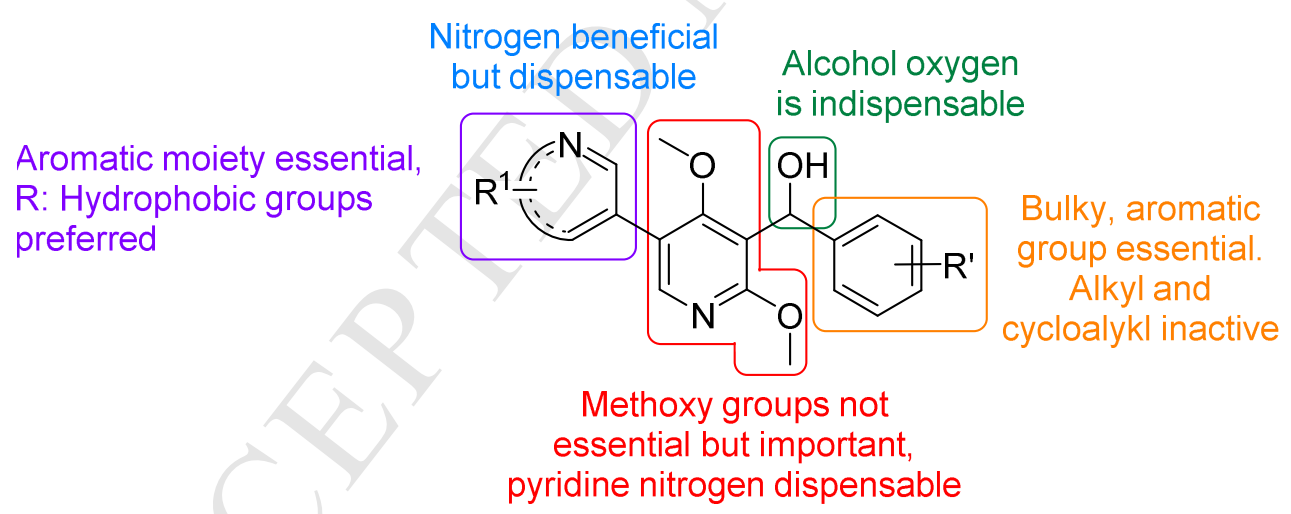

Figure 2: Summary of the explored SAR of the dimethoxypyridine compound class in starvation-induced autophagy.

\section{Biological Validation}

DMP-1 inhibited starvation-induced autophagy potently and dosedependently, as assessed by the reduction in LC3 puncta in our primary screening assay (Figure $3 \mathrm{~A}$ and $3 \mathrm{~B}$ ). To further validate DMP-1 as an autophagy inhibitor, we studied its effect on the key autophagy markers: LC3 
lipidation and p62 degradation. After the induction of autophagy, LC3 is lipidated with phosphatidylethanolamine to form LC3-II, ${ }^{28}$ an effect that should be reversed by an autophagy inhibitor that does not target autophagosomelysosome fusion. DMP-1 inhibited LC3 lipidation dose-dependently as assessed by western blot analysis (Figure 3C). p62 (also known as sequestome 1) acts as a chaperone to target proteins for degradation by the autophagic machinery, where it is also degraded. Autophagy inhibitors inhibit the degradation of p62 when autophagy is induced. DMP-1 inhibited the degradation of p62, confirming its ability to inhibit autophagic flux (Figure 3C).

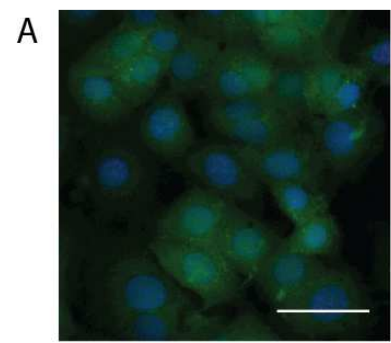

Fed

B
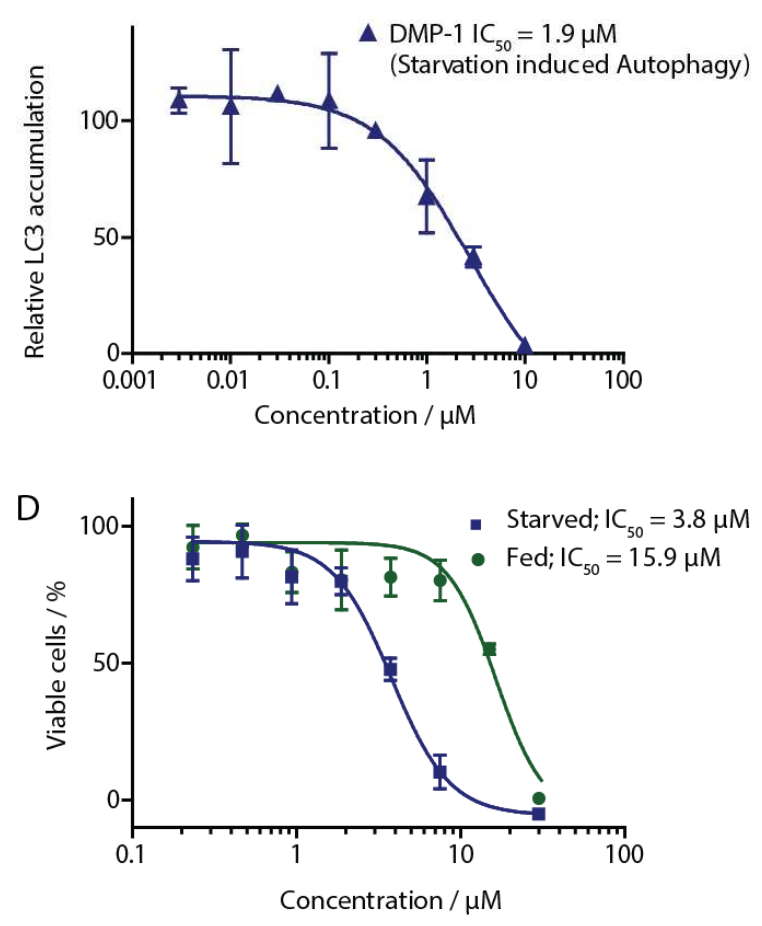

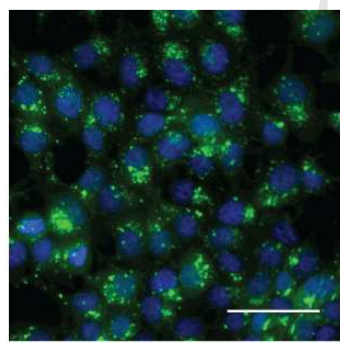

Starved, 1 MM DMP-1

C

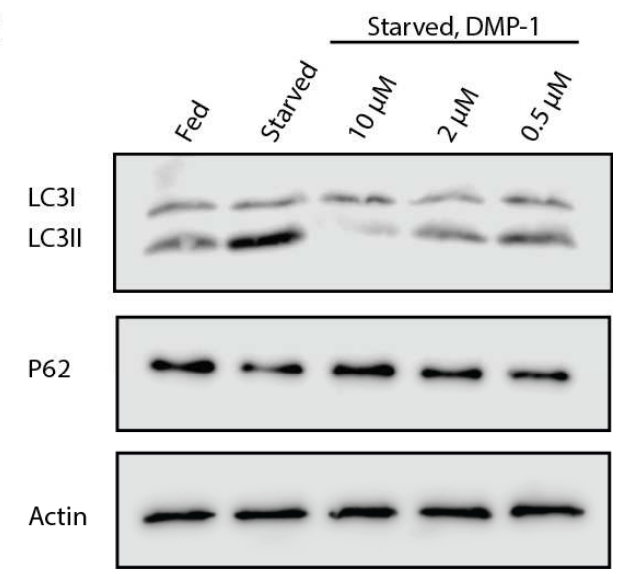

$\mathrm{E}$

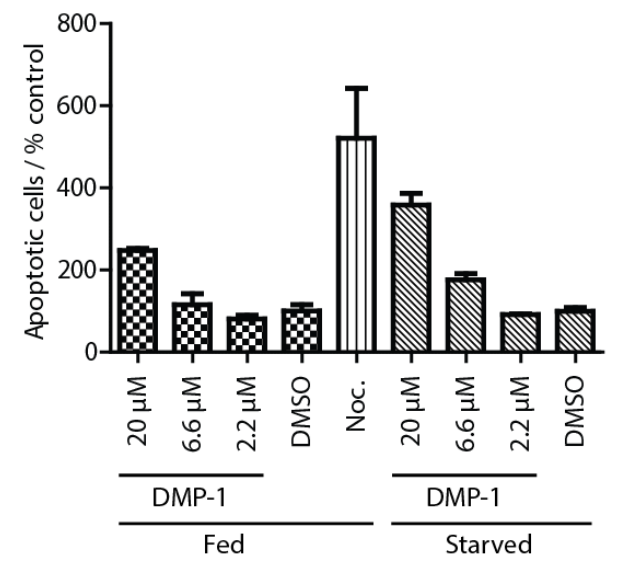


Figure 3: Phenotypic validation of DMP-1 as an autophagy inhibitor. A: Fluorescence microscopy images of the starvation-induced autophagy screen for inhibition of eGFP-LC3 accumulation. Fed = DMSO control incubated in full media (MEM) as positive control. Starved = autophagy was induced by amino acid withdrawal (EBSS). DMP-1 reverts the phenotype in a dose dependent manner. Scale bar $=50 \mu \mathrm{m}$. B: Dose-dependent inhibition of amino acid starvation induced eGFP-LC3 accumulation by DMP-1. Data is mean $\pm \mathrm{SD}, n \geq 3$; representative graph shown. C: Inhibition of LC3 lipidation and p62 degradation by DMP-1 in MCF7-eGFP-LC3 cells. Starvation-induced autophagy induces lipidation of LC3-I to LC3-II and degradation of p62. DMP1 inhibits both effects in a dose-dependent manner. $n \geq 3$, representative blot shown. D and E: DMP-1 induces cell death in starved cells by means of apoptosis. D: Treatment of MCF7-eGFP-LC3 cells under starved conditions (EBSS) or fed conditions (MEM) with DMP-1. Under starvation conditions survival is reduced. Cytotoxicity was assessed by means of a WST-1 assay. Data points are mean $\pm S D, n \geq 3$, representative graphs shown. E: DMP-1 dose dependently induces apoptosis in starved cells. Apoptosis was assessed by using a selective caspase $3 / 7$ probe. The experiment was performed with an Incucyte Zoom live-cell imaging device. Noc. = Nocodazole $(10 \mu \mathrm{M})$. Data are presented as a percent of the DMSO control. Data points are mean \pm SD, $n \geq 3$, representative bars shown.

As autophagy is a cytoprotective mechanism that is activated in conditions of cellular stress, autophagy inhibition is reported to render cells more sensitive to the effects of starvation. ${ }^{34}$ In line with this expectation, DMP-1 selectively inhibited the growth of starved MCF7-eGFP-LC3 cells compared to fed cells as assessed by a WST-1 proliferation assay (Figure 3D). It has been reported that autophagy inhibition causes cells to die via apoptosis. ${ }^{35}$ MCF7 cells treated with DMP-1 showed apoptotic cell death under fed as well as under starved conditions, as assessed by live cell imaging of a caspase 3/7 selective probe, which releases a DNA intercalating dye that labels the nuclei of apoptotic cells (Figure 3E). In order to delineate the mode of action of the DMPs further, their ability to inhibit autophagy induced by the pharmacological 
inhibition of mTOR by Rapamycin was assessed in MCF7-eGFP-LC3 cells. Neither DMP-1 nor any of its analogues inhibited Rapamycin-induced autophagy, which suggests that they act upstream or independently of mTOR (data not shown).

To identify the molecular target(s) of DMP-1, we employed a newly developed machine learning approach using random forest technology and the CATS2 topological pharmacophore descriptors. ${ }^{36,37}$ The built regression random forest models use an ensemble of decision trees to provide a consensus affinity value prediction $\left[\mathrm{p} A\right.$ ffinity $=-\log \left(\mathrm{IC}_{50}\right.$ or $\left.K_{\mathrm{D}}\right)$ ] for a range of $>1000$ human drug targets extensively curated from ChEMBL. ${ }^{38}$ Through these models, the cannabinoid receptor 1 (CB1) was predicted as macromolecular target for DMP-1 ( $\mathrm{p}$ Affinity = 6.8) with high confidence. Indeed, testing of DMP-1 in a CB1 functional assay (Cerep, France) revealed moderate antagonist effect $\left(\mathrm{IC}_{50}=3.1 \pm 0.08 \mu \mathrm{M} ; K_{\mathrm{B}}=0.32 \mu \mathrm{M}\right.$; Figure 3$)$, yet fully in line with our regression model (experimental $p$ Affinity $=6.5$ ). A radioligand displacement assay further confirmed binding of DMP-1 to $\mathrm{CB} 1\left(\mathrm{IC}_{50}=4.3\right.$ $\left.\mu \mathrm{M}, K_{\mathrm{i}}=3.2 \mu \mathrm{M}, n \mathrm{Hill}=1.1\right)$.

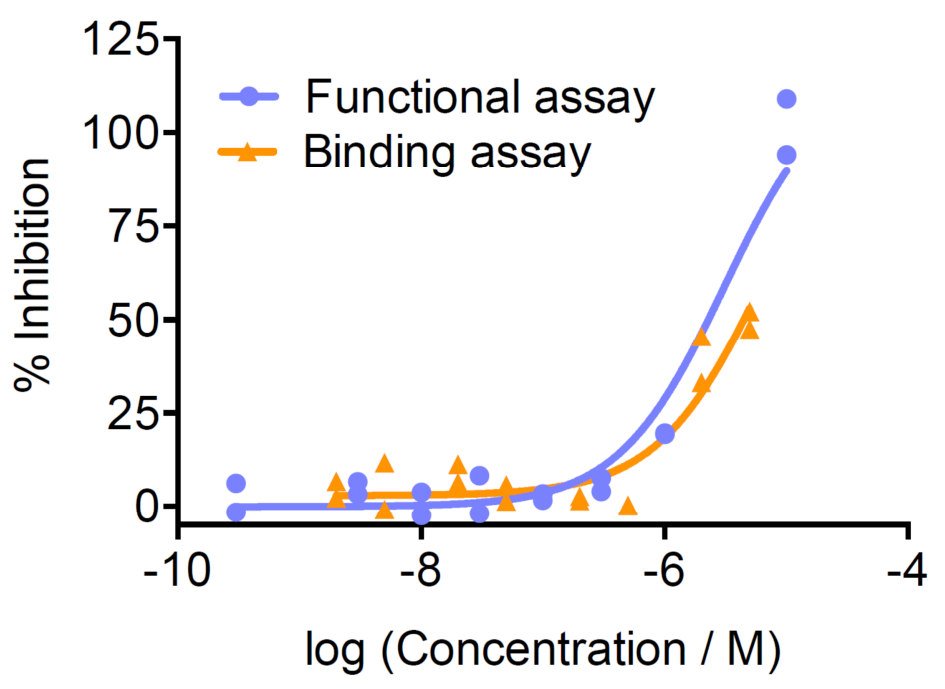

Figure 3: DMP-1 is a cannabinoid 1 receptor antagonist. Functional assay: $\mathrm{IC}_{50}=3.1 \pm 0.08 \mu \mathrm{M} ; K_{\mathrm{B}}=0.32 \mu \mathrm{M}, n=2$. Control: AM281, IC $\mathrm{C}_{50}=28 \mathrm{nM}$. Binding assay: $\mathrm{IC}_{50}=4.3 \mu \mathrm{M}, K_{\mathrm{i}}=3.2 \mu \mathrm{M}, n \mathrm{Hill}=1.1, n=2$. Control: $\mathrm{R}(+)$ WIN-55,212-2, $I_{50}=0.53 \mu \mathrm{M}$. 
CB1 has previously been linked to autophagy, ${ }^{39}$ and $C B 1$ antagonists have been suggested to weakly induce autophagy, which is contradictory to our findings. We tested a CB1 antagonist (Rimonabant) and an inverse agonist (Ipinabant) for their ability to inhibit starvation-induced autophagy. Rimonabant weakly inhibited starvation-induced autophagy $\left(\mathrm{IC}_{50}=4.1 \pm 0.7\right.$ $\mu \mathrm{M})$, while Ipinabant did not. Considering the fact that both compounds target CB1 with nanomolar potency, but only show moderate autophagy-modulating capabilities, it is unlikely that the ability of DMP-1 to inhibit autophagy stems only from its ability to inhibit CB1. Additionally, DMP-1 was also tested in a full kinase panel at Life Technologies (Thermo Fischer). No kinase was inhibited more than $30 \%$ at a concentration of $5 \mu \mathrm{M}$, including the MAP4K4, the target of Militarinone derivative 1. Further efforts to elucidate the molecular target(s) of DMP-1 are currently ongoing and will be reported in due course.

\section{Conclusion}

We reported the discovery, development and biological validation of 2,4dimethoxypyridine-based autophagy inhibitors. This compound class was developed from Militarinone-inspired MAP4K4 inhibitors, ${ }^{24}$ demonstrating the versatility of the BIOS principle for the development of biologically active small molecules. The most potent compound, DMP-1, inhibited starvation but not rapamycin-induced autophagic flux, suggesting that it acts upstream or independently of mTOR. Computational target identification correctly identified the CB1 receptor as a molecular target of DMP-1, however this could not be validated using clinically approved CB1 antagonists or inverse agonists, highlighting the great challenge that target ID can pose in phenotypic screening campaigns. Nonetheless, DMP-1 and analogues thereof expand the toolkit of autophagy inhibitors available to study this highly complex process and may provide new starting points for drug discovery programmes in cancer or neurodegenerative diseases.

\section{Acknowledgements}


This research was supported by the Max-Planck-Gesellschaft. L.R. is grateful to the Boehringer Ingelheim Fonds for a fellowship. L.L. is grateful to the Alexander von Humboldt Foundation for a fellowship. T.R. is a Marie Skłodowska-Curie Fellow (Grant 743640). D.J.F. is grateful to the European Commission for a Marie Skłodowska-Curie European Fellowship (Grant 794259). G.J.L.B. acknowledges Fundação Ciência Tecnologia (iFCT), Royal Society (URF) and the European Research Council (ERC StG Taglt) for funding.

\section{References}

(1) Rubinsztein, D. C.; Shpilka, T.; Elazar, Z. Curr. Biol. 2012, 22, 34

(2) Klionsky, D. J. Science 2000, 290, 1717-1721

(3) Boya, P.; Reggiori, F.; Codogno, P. Nat. Cell Biol. 2013, 15, 713-720

(4) Berger, Z.; Ravikumar, B.; Menzies, F. M.; Oroz, L. G.; Underwood, B. R.; Pangalos, M. N.; Schmitt, I.; Wullner, U.; Evert, B. O.; O'Kane, C. J. et al. Hum. Mol. Genet. 2006, 15, 433-442

(5) Ravikumar, B. Hum. Mol. Genet. 2002, 11, 1107-1117

(6) Webb, J. L.; Ravikumar, B.; Atkins, J.; Skepper, J. N.; Rubinsztein, D. C. J. Biol. Chem. 2003, 278, 25009-25013

(7) Chen, H.-Y.; White, E. Cancer Prev. Res. 2011, 4, 973-983,

(8) White, E.; Karp, C.; Strohecker, A. M.; Guo, Y.; Mathew, R. Curr. Op. Cell Biol. 2010, 22, 212-217

(9) Mathew, R.; Karp, C. M.; Beaudoin, B.; Vuong, N.; Chen, G.; Chen, H.-Y.; Bray, K.; Reddy, A.; Bhanot, G.; Gelinas, C. et al. Cell 2009, 137, 1062-1075 (10) Degenhardt, K.; Mathew, R.; Beaudoin, B.; Bray, K.; Anderson, D.; Chen, G.; Mukherjee, C.; Shi, Y.; Gélinas, C.; Fan, Y. et al. Cancer Cell 2006, $10,51-64$

(11) Hanahan, D.; Weinberg, R. A. Cell 2011, 144, 646-674

(12) Kimmelman, A. C. Gen. Dev. 2011, 25, 1999-2010,

(13) Choi, K. S. Exp. Mol. Med. 2012, 44, 109-120,

(14) Rubinsztein, D. C.; Codogno, P.; Levine, B. Nat. Rev. Drug Discov. 2012, 11, 709-730 
(15) Levine, B.; Kroemer, G. Cell 2008, 132, 27-42

(16) Lebovitz, C. B.; DeVorkin, L.; Bosc, D.; Rothe, K.; Singh, J.; Bally, M.; Jiang, X.; Young, R. N.; Lum, J. J.; Gorski, S. M. Autophagy 2015, 11, 19491952

(17) Rubinsztein, D. C.; Gestwicki, J. E.; Murphy, L. O.; Klionsky, D. J. Nat. Rev. Drug Discov. 2007, 6, 304-312

(18) Moffat, J. G.; Rudolph, J.; Bailey, D. Nat. Rev. Drug Discov. 2014, 13, 588-602

(19) Swinney, D. C.; Anthony, J. Nat. Rev. Drug Discov. 2011, 10, 507-519

(20) Gough, A.; Shun, T. Y.; Lansing Taylor, D.; Schurdak, M. Methods 2016, 96, 12-26

(21) O'Connor, C. J.; Laraia, L.; Spring, D. R. Chem. Soc. Rev. 2011, 40, 4332-4345

(22) Kaiser, M.; Wetzel, S.; Kumar, K.; Waldmann, H. Cell. Mol. Life Sci. 2008, 65, 1186-1201

(23) Wetzel, S.; Bon, R. S.; Kumar, K.; Waldmann, H. Angew. Chem. Int. Ed. 2011, 50, 10800-10826

(24) Schröder, P.; Förster, T.; Kleine, S.; Becker, C.; Richters, A.; Ziegler, S.; Rauh, D.; Kumar, K.; Waldmann, H. Angew. Chem. Int. Ed. 2015, 54, 1239812403

(25) Balgi, A. D.; Fonseca, B. D.; Donohue, E.; Tsang, T. C. F.; Lajoie, P.; Proud, C. G.; Nabi, I. R.; Roberge, M. PLoS ONE 2009, 4, e7124,

(26) Peppard, J. V.; Rugg, C.; Smicker, M.; Dureuil, C.; Ronan, B.; Flamand, O.; Durand, L.; Pasquier, B. Curr. Chem. Genom. Transl. Med. 2014, 8, 3-15, (27) Konstantinidis, G.; Sievers, S.; Wu, Y.-W. Methods Mol. Biol. 2018, ASAP

(28) Mizushima, N.; Yoshimori, T.; Ohsumi, Y. Annu. Rev. Cell Dev. Biol. 2011, 27, 107-132,

(29) Zhou, J.; Tan, S.-H.; Nicolas, V.; Bauvy, C.; Yang, N.-D.; Zhang, J.; Xue, Y.; Codogno, P.; Shen, H.-M. Cell Res. 2013, 23, 508-523

(30) Laraia, L.; Ohsawa, K.; Konstantinidis, G.; Robke, L.; Wu, Y.-W.; Kumar, K.; Waldmann, H. Angew. Chem. Int. Ed. 2017, 56, 2145-2150 
(31) Robke, L.; Laraia, L.; Carnero Corrales, M. A.; Konstantinidis, G.; Muroi, M.; Richters, A.; Winzker, M.; Engbring, T.; Tomassi, S. et al. Angew. Chem. Int. Ed. 2017, 56, 8153-8157

(32) Robke, L.; Futamura, Y.; Konstantinidis, G.; Wilke, J.; Aono, H.; Mahmoud, Z.; Watanabe, N.; Wu, Y.-W.; Osada, H.; Laraia, L. et al. Chem. Sci. 2018, 9, 3014-3022,

(33) Laraia, L.; Waldmann, H. Drug Discov. Today 2017, 23, 75-82

(34) Liu, J.; Xia, H.; Kim, M.; Xu, L.; Li, Y.; Zhang, L.; Cai, Y.; Norberg, H. V.; Zhang, T.; Furuya, T. et al. Cell 2011, 147, 223-234

(35) Maiuri, M. C.; Zalckvar, E.; Kimchi, A.; Kroemer, G. Nat. Rev. Mol. Cell Biol. 2007, 8, 741-752

(36) Gonçalo, B.; Tiago, R.; Markus, W.; Jakob, R.; Eduardo H. G., da Cruz; Marta C., M.; Susana A., L.; Andreas, K.; Francisco, C.; Eufrânio, N. da Silva Júnior, et al. ChemRxiv, 2018

(37) Reutlinger, M.; Koch, C. P.; Reker, D.; Todoroff, N.; Schneider, P.; Rodrigues, T.; Schneider, G. Mol. Inf. 2013, 32, 133-138

(38) Bento, A. P.; Gaulton, A.; Hersey, A.; Bellis, L. J.; Chambers, J.; Davies, M.; Krüger, F. A.; Light, Y.; Mak, L.; McGlinchey, S. et al. Nuc. Acids Res. 2014, 42, D1083-90,

(39) Hiebel, C.; Kromm, T.; Stark, M.; Behl, C. J. Neurochem. 2014, 131, 484-497 


\section{ACCEPTED MANUSCRIPT}

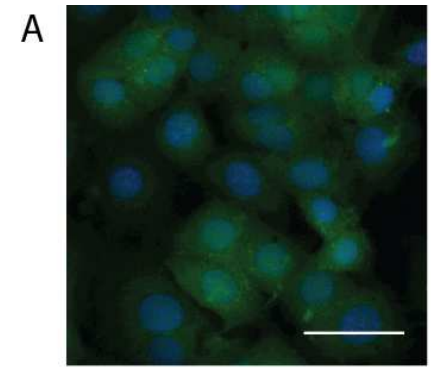

Fed

B
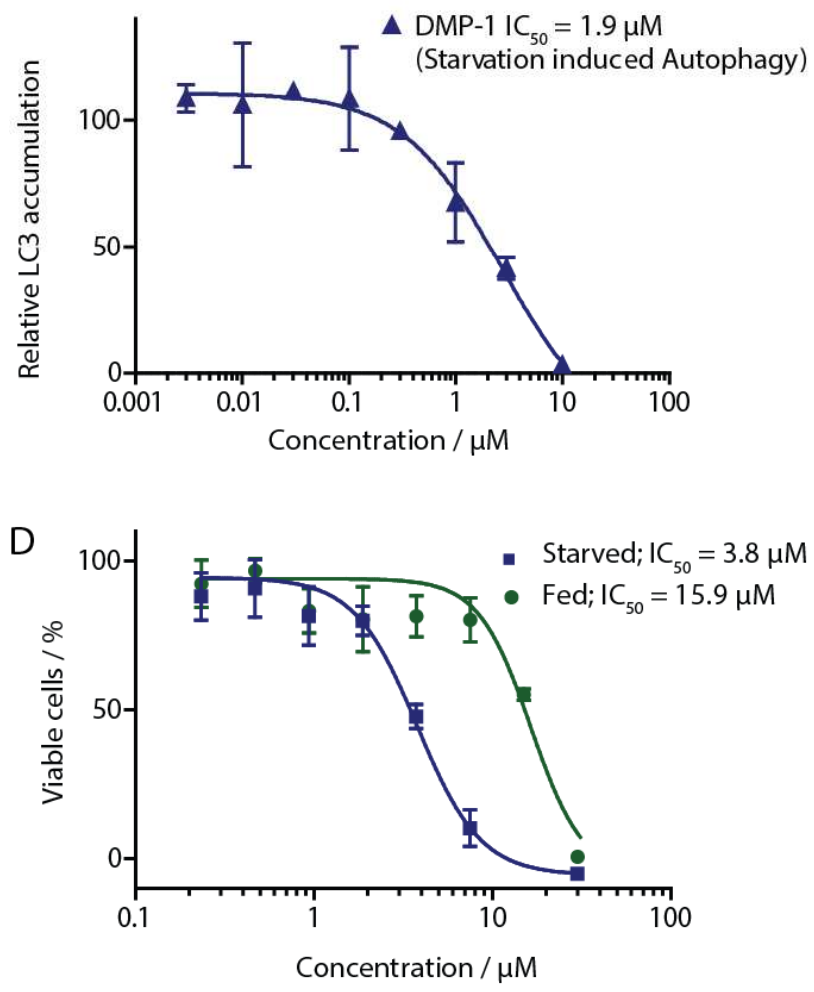

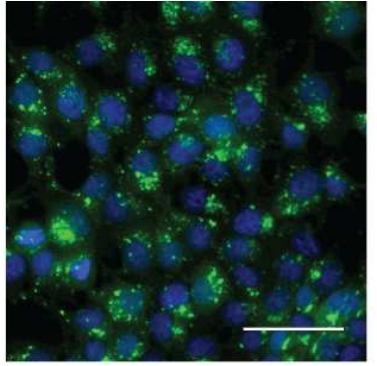

Starved, $1 \mu$ M DMP-1

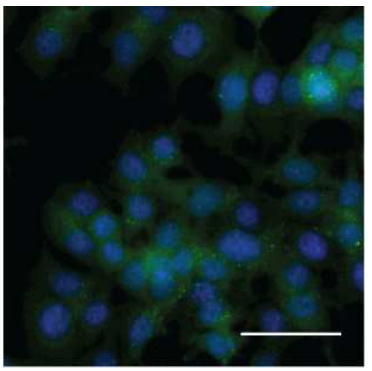

Starved, $10 \mu \mathrm{M} \mathrm{DMP-1}$

C
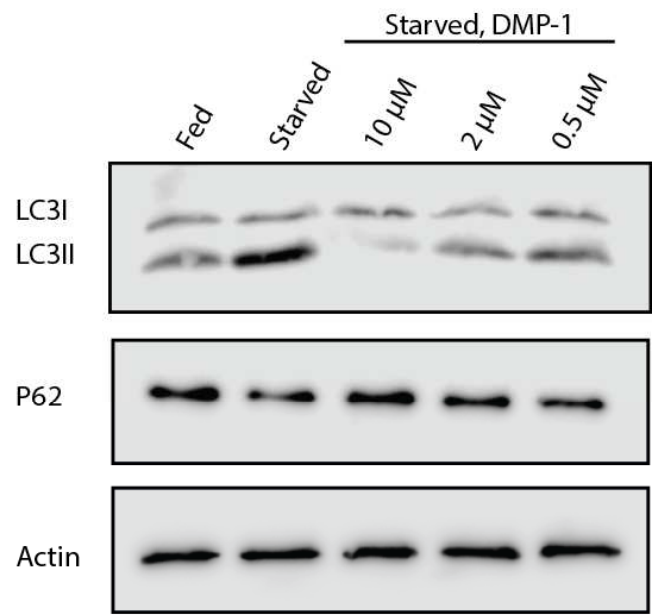

E

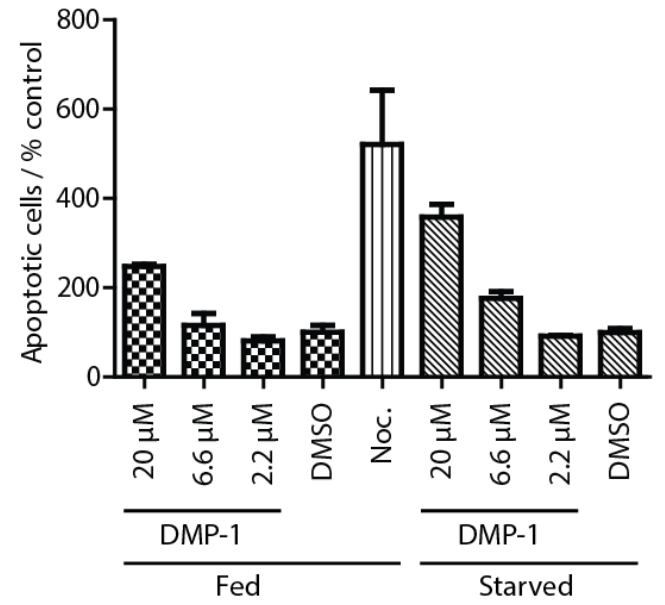




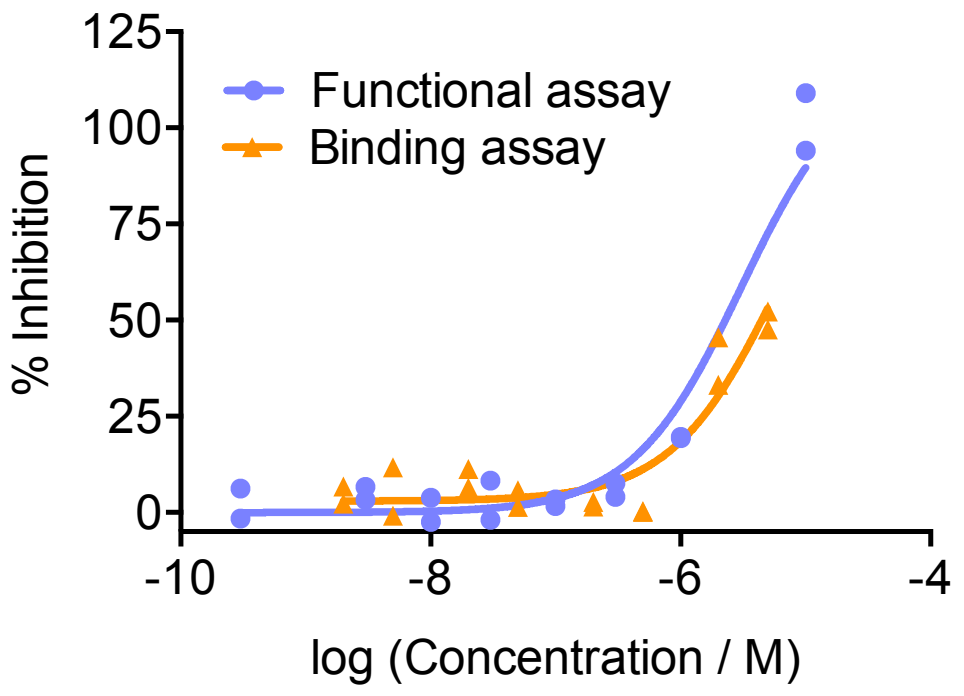

